\title{
On the Arteria Maxillaris which Passes Medial to the Pterygoideus Lateralis Muscle of the Japanese - Patterns of Origin of the Inferior Alveolar, the Masseteric and the Posterior Temporal Arteries -
}

\author{
By
}

\author{
Fumihiko SUWA, Akimichi TAKEMURA, Yhuji EHARA, Noriaki TAKEDA \\ and Mitsuhiro MASU
}

Department of Anatomy, Osaka Dental University, 5-31, Otemae 1-chome, Chuo-ku, Osaka 540, Japan (Director: Prof. Yoshikuni Ohta)

- Received for Publication, June 25, 1990-

Key Words: Maxillary artery, Pterygoid muscles, Alveolar artery, Masseteric artery, Temporal arteries

\begin{abstract}
Summary: Variations in the patterns of origin of the inferior alveolar, the posterior deep temporal and the masseteric arteries when the maxillary artery passed medial to the pterygoideus lateralis muscle on 30 sides of 24 heads $(10.8 \%)$ among a total of 278 sides of 139 heads of the Japanese, were investigated. The results obtained may be summarized as follows:

1. The maxillary artery gave off a common trunk between the inferior alveolar and the posterior deep temporal $(\mathbf{7 6 . 7 \%})$, the latter distal to the former $(16.7 \%)$ and in contact with their origins $(6.7 \%)$. The masseteric artery always arose from the posterior deep temporal in 24 heads.

2. The above-mentioned common trunk was observed in $52.1 \%$ of males and $47.9 \%$ of females, as well as on $56.5 \%$ of left sides and $43.5 \%$ of right sides.

3. It can be said that the maxillary artery always passed medial to the pterygoideus lateralis, when the inferior alveolar arose in common with the posterior deep temporal.
\end{abstract}

Recently, it has become more important to examine the course of the maxillary artery in the infratemporal fossa in relation to clinical procedures such as puncture by EMG rods and trigeminal ganglion blocking. Many investigators have described the general course and ramifications of the maxillary artery which passes lateral to the pterygoideus lateralis muscle. However, the passage of this artery medial to this muscle has scarcely been surveyed in these terms including the topographical relations between the mandibular nerve and pterygoideus muscles. The present authors therefore attempted to elucidate the topographical relations between the pterygoideus lateralis muscle and the inferior alveolar, the masseteric and the posterior temporal arteries by undertaking examinations of a large sample of human materials. The findings obtained are discussed in comparison with those for other mammals.

\section{Materials and Methods}

In the present investigation, 139 cadavers (278 sides) of Japanese for dissection were employed. They comprised 71 males (142 sides) (41 to 95 years old) and 68 females (136 sides) (50 to 93 years old) as shown in Table 1.

Table 1. Age of the cadavers observed.

\begin{tabular}{cccccccc}
\hline & Ages & & & & \\
& $40 \sim 49$ & $50 \sim 59$ & $60 \sim 69$ & $70 \sim 79$ & $80 \sim 89$ & $90 \sim$ & Total \\
\hline Male & 1 & 7 & 8 & 27 & 26 & 2 & 71 \\
\hline Female & 0 & 5 & 7 & 26 & 27 & 3 & 68 \\
\hline Total & 1 & 12 & 15 & 53 & 53 & 5 & 139 \\
\hline
\end{tabular}

\section{Findings}

1. Topographical relations between the course of the maxillary artery and the pterygoideus lateralis muscle.

The maxillary artery passed lateral to the pterygoideus lateralis muscle on 248 sides (bilaterally in 115 heads and unilaterally in 18 heads) of 133 heads 
Table 2. Topographical relations between the maxillary artery and the pterygoideus lateralis muscle.

\begin{tabular}{|c|c|c|c|c|c|}
\hline & $\begin{array}{l}\text { Lateral course } \\
\text { bilaterally }\end{array}$ & $\begin{array}{l}\text { Lateral (1) o } \\
\text { course unila }\end{array}$ & lial (m) & $\begin{array}{l}\text { Medial course } \\
\text { bilaterally }\end{array}$ & Total \\
\hline \multirow{4}{*}{ Male } & \multirow{4}{*}{59} & Right (m) & \multirow{4}{*}{9} & \multirow{4}{*}{3} & \multirow{4}{*}{71} \\
\hline & & Left (l) 6 & & & \\
\hline & & Right (l) & & & \\
\hline & & Left (m) 3 & & & \\
\hline \multirow{4}{*}{ Female } & \multirow{4}{*}{56} & Right (m) & \multirow{4}{*}{9} & \multirow{4}{*}{3} & \multirow{4}{*}{68} \\
\hline & & Left (l) 5 & & & \\
\hline & & Bight (l) & & & \\
\hline & & Left (m) 4 & & & \\
\hline Total & 115 & 18 & & 6 & 139 \\
\hline
\end{tabular}

among the total of 278 sides of 139 heads (cadavers) observed. The origin of the inferior alveolar artery separated from that of the posterior deep temporal artery which gave rise to the masseteric artery (Fig. 1a).

The maxillary artery passed medial to the lower head of the pterygoideus lateralis muscle on 30 sides (bilaterally in 6 heads and unilaterally in 18 heads) of 24 heads, which included 12 males (bilaterally in 3 ) and 12 females (bilaterally in 3) (Figs. $1 \mathrm{~b}$ and 2). Details for the above 18 heads are shown in Table 2.

2. The maxillary artery passing medial to the pterygoideus lateralis muscle.

The maxillary artery running on the medial surface of the mandibular ramus gave rise to the inferior alveolar and the posterior deep temporal arteries independently or in common with each other, and reached the inferior margin of the origin of the lower head of the pterygoideus lateralis. The maxillary artery continued to run obliquely from posterolateral to anteromedial along the inferior margin of this head up to its upper margin, where the artery bent forwards. It then passed lateralwards between the upper and lower heads and continued between the upper head and the insertion of the temporalis muscle towards the sphenopalatine fossa. On 28 of the above 30 sides, in which the maxillary artery passed medial to the pterygoideus lateralis, it took a similar course to that mentioned above. However, on the remaining 2 sides, it followed a similar course to that mentioned above from a position between the lower and upper heads after penetrating the venter of the lower head (Fig. 2). In all of the cases described above, the masseteric artery never arose directly from the maxillary artery, but from the posterior deep temporal artery (Figs. 1b and 2).

3. Origins of the inferior alveolar and the posterior deep temporal arteries when the maxillary artery passed medial to the pterygoideus lateralis muscle.

On 23 of the 30 sides ( 20 in the 24 heads mentioned above), a common trunk between the inferior alveolar and the posterior deep temporal arteries diverged antero-infero-laterally from the lateral wall of the maxillary artery (Fig. 1b); and on 5 sides ( 3 heads), the inferior alveolar arose independently from the inferior or lateral wall of the maxillary and the posterior deep temporal anterosuperiorly from the inferior or lateral wall independently. On both sides of the remaining one head, these two arteries diverged in contact with each other from the maxillary as described above (Table 3).

The common trunk between the inferior alveolar and the posterior deep temporal was found bilaterally in 3 heads ( 2 males and one female) of the above 20 heads, and unilaterally) in 8 heads ( 5 on the right and 3 on the left) of the other males and in 9 heads ( 5 on the right and 4 on the left) of the other females. On 5 sides of 3 heads, in which both arteries diverged and separated from each other, it was found bilaterally in one male and female head each. It was not found unilaterally in the female head, but on the right side of the remaining one male head. Both arteries diverging at the same position on the maxillary were found only in one female bilaterally (Table 3 ).

\section{Discussion}

Long (1891), Thomson (1891) and Lauber (1901) investigated the morphology of the maxillary artery in man. The latter two scholars described both the medial and lateral courses of this artery in relation to the pterygoideus lateralis muscle. Adachi (1928) suggested a race difference, noting that this artery passed lateral to the muscle in more than $90 \%$ of the Japanese. Fujita (1932), Takarada (1958), Ikakura (1961) and Iwamoto et al. (1981) also later reported similar findings 
Table 3. Arising aspects of the inferior alveolar, the posterior deep temporal and the masseteric arteries when the maxillary artery passes medial to the pterygoideus lateralis muscle.

\begin{tabular}{|c|c|c|c|c|c|c|c|c|c|c|c|c|c|}
\hline & \multicolumn{5}{|c|}{ Male } & \multicolumn{5}{|c|}{ Female } & \multicolumn{2}{|c|}{ Male + Female } & \multirow{2}{*}{ Total } \\
\hline & both & right & left & $\begin{array}{l}\text { right } \\
\text { total }\end{array}$ & $\begin{array}{l}\text { left } \\
\text { total }\end{array}$ & both & right & left & $\begin{array}{l}\text { right } \\
\text { total }\end{array}$ & $\begin{array}{l}\text { left } \\
\text { total }\end{array}$ & $\begin{array}{l}\text { right } \\
\text { total }\end{array}$ & $\begin{array}{l}\text { left } \\
\text { total }\end{array}$ & \\
\hline $\begin{array}{l}\text { A common trunk between th } \\
\text { inferior alveolar and the } \\
\text { posterior deep temporal }\end{array}$ & $\begin{array}{c}2 \\
(4)\end{array}$ & $\begin{array}{c}5 \\
(5)\end{array}$ & $\begin{array}{c}3 \\
(3)\end{array}$ & (7) & (5) & $\begin{array}{c}1 \\
(2)\end{array}$ & $\begin{array}{c}5 \\
(5)\end{array}$ & $\begin{array}{c}4 \\
(4)\end{array}$ & (6) & (5) & (13) & $(10)$ & $\begin{array}{c}20 \\
(23)\end{array}$ \\
\hline $\begin{array}{l}\text { In contact with each other } \\
\text { (at the same location) }\end{array}$ & $\begin{array}{c}0 \\
(0)\end{array}$ & $\begin{array}{c}0 \\
(0)\end{array}$ & $\begin{array}{c}0 \\
(0)\end{array}$ & $(0)$ & $(0)$ & $\begin{array}{c}1 \\
\text { (2) }\end{array}$ & $\begin{array}{c}0 \\
(0)\end{array}$ & $\begin{array}{c}0 \\
(0)\end{array}$ & (1) & (1) & (1) & (1) & $\begin{array}{c}1 \\
(2)\end{array}$ \\
\hline $\begin{array}{l}\text { Separating the arising of } \\
\text { the inferior alveolar from } \\
\text { it of the posterior deep } \\
\text { temporal }\end{array}$ & $\begin{array}{l}1 \\
(2)\end{array}$ & $\begin{array}{l}1 \\
(1)\end{array}$ & $\begin{array}{l}0 \\
(0)\end{array}$ & (2) & (1) & $\begin{array}{l}1 \\
(2)\end{array}$ & $\begin{array}{l}0 \\
(0)\end{array}$ & $\begin{array}{l}0 \\
(0)\end{array}$ & (1) & (1) & (3) & (2) & $\begin{array}{l}3 \\
(5)\end{array}$ \\
\hline Total & $\begin{array}{c}3 \\
(6)\end{array}$ & $\begin{array}{c}6 \\
(6)\end{array}$ & $\begin{array}{c}3 \\
(3)\end{array}$ & (9) & (6) & $\begin{array}{c}3 \\
(6)\end{array}$ & $\begin{array}{c}5 \\
(5)\end{array}$ & $\begin{array}{c}4 \\
(4)\end{array}$ & (8) & (7) & (17) & (13) & $\begin{array}{c}24 \\
(30)\end{array}$ \\
\hline
\end{tabular}

The masseteric artery arises from the posterior deep temporal in all heads observed. ( ): number of sides

following Adachi's suggestion. Lurje (1947) reported that the maxillary artery passed lateral to the pterygoideus lateralis muscle in doliocephalic skulls $(92.6 \%)$ and medial to it in brachyocephalic skulls $(69 \%)$ of Russians. He also suggested that attention should be paid to the medial course of the maxillary artery in cases undergoing an anesthetic blocking procedure for the trigeminal ganglion. Takemura et al. (1983) reported that the maxillary artery passing medial to this muscle in some examples penetrated the ramifications of the mandibular nerve. Lippert and Pabst (1985) described the topographical relations of the maxillary, the inferior alveolar, the middle meningeal arteries and the main branches of the mandibular nerve. These investigators, however, did not give details of variations in the origins of these arteries which may have occurred with the variable courses of the maxillary artery. They scarcely paid attention to the maxillary artery passing medial to the pterygoideus lateralis muscle because the artery passing lateral to it in the majority of all examples observed was reported as the normal pattern.

1. Frequency of appearance of the medial passage of the maxillary artery in relation to the pterygoideus lateralis muscle.

The appearance frequency was found to be $10.8 \%$ on average (30 of 278 sides; viz., in 24 of 139 heads). This value was similar to those given by Fujita (1932), Takarada (1958), and Ikakura (1961), but higher than that of about $6 \%$ given by Adachi (1928), as shown in Table 4 . The value was essentially independent of sex: $10.6 \%$ in males and $11.1 \%$ in females.

Table 4. Appearance frequencies when the maxillary artery passes medial to the pterygoideus lateralis muscle.

\begin{tabular}{lrrlll}
\hline \multicolumn{1}{c}{ Races } & $\mathrm{N}$ & $\mathrm{n}$ & (Frequencies) & \multicolumn{1}{c}{ Authors } & Year \\
\hline English & 93 & 43 & $(46.2 \%)$ & Long & 1891 \\
English & 447 & 200 & $(44.7 \%)$ & Thomson & 1891 \\
Russian & 200 & 65 & $(32.5 \%)$ & Lurje & 1947 \\
American-White & 147 & 67 & $(45.6 \%)$ & Lasker et al. & 1951 \\
American-Negro & 67 & 21 & $(31.3 \%)$ & Opdyke et al. & 1951 \\
\hline Australian & 200 & 183 & $(91.5 \%)$ & Lauber & 1901 \\
\hline & 331 & 21 & $(6.3 \%)$ & Adachi & 1927 \\
& 119 & 12 & $(10.1 \%)$ & Fujita & 1932 \\
Japanese & 120 & 11 & $(9.2 \%)$ & Takarada & 1953 \\
& 160 & 15 & $(9.4 \%)$ & Ikakura & 1961 \\
& 158 & 11 & $(7.0 \%)$ & Iwamoto et al. & 1981 \\
& 278 & 30 & $(10.8 \%)$ & Authors & 1990 \\
\hline
\end{tabular}


In the 24 heads, in which the maxillary artery passed medial to the pterygoideus lateralis muscle, no sex difference was observed in the frequency by right and left side in the bilateral cases. The appearance frequency in the unilateral cases was $67 \%$ on the right and $33 \%$ on the left in males, and $56 \%$ on the right and $44 \%$ on the left in females. The value was thus higher on the right side in both sexes, especially being twice as high on the right side of males, similarly to the data reported previously by other investigators.

2. Relationship between the maxillary artery passing medial to the pterygoideus lateralis muscle and the origins of its ramifications.

The maxillary artery always passed medial to the pterygoideus lateralis muscle after bending at the inferior margin of the origin of the lower head. However, when the artery passed lateral to the muscle, it gave rise to the inferior alveolar and a common trunk between the masseteric and the posterior deep temporal at a similar location. Centering around this location, a difference was found in the patterns of origin of these three arteries. The masseteric artery arose from the posterior deep temporal in all cases, in which the maxillary artery passed medial to the muscle. Three types of origins of the inferior alveolar and the posterior deep temporal were observed, as shown in Table 3. These were: via a common trunk between both arteries (76.7\%), the latter distal to the former from the maxillary artery separating from each other $(16.7 \%)$, and in contact with their origins $(6.7 \%)$. These findings may reflect a tendency for these three arteries to form a common trunk when the parent artery passes medial to the pterygoideus lateralis. Similarly, Takarada (1958) reported 4 cases, in which the inferior alveolar and the posterior deep temporal arose via a common trunk when the maxillary artery passed medial to the muscle. In such cases, this location should be favorable and helpful for these three arteries to supply the structures always situated lateral to the pterygoideus lateralis. On the other hand, when the parent artery passes lateral to the muscle, these arteries never make a common trunk with each other, although the masseteric exceptionally arises from the posterior deep temporal. Accordingly, it can be said that the maxillary always took a course medial to the pterygoideus medialis when a common trunk between the inferior alveolar and the posterior deep temporal was found. In other mammals, the maxillary artery passes medial to this muscle in the dog (Suwa et al., 1978) and the cat (Takemura, 1982 and Saitoh, 1988), although this muscle is extremely underdeveloped in the carnivora, and the rabbit (Kimura, 1982), and the above common trunk is also found. However, the maxillary passed lateral to the muscle in all examples observed in the crab-eating monkey (Suwa, 1981) and the above arteries arose in- dependently. The above suggestion given by the author may be significant and applicable to these cases in both man and other mammals.

3. Other features associated with the medial passage of the maxillary artery.

As shown in Table 3, a distinct difference between males and females was not found in the origins of the inferior alveolar and the posterior deep temporal. Cases of both arteries being in contact with each other at their origins were not found in males and in less than $10 \%$ of females. No case was observed where the origin of the inferior alveolar was interchanged with that of the posterior deep temporal. Takarada (1958) reported that a common trunk between the two arteries was found in 7 sides, being a little higher than that found by the present authors. The common trunk was encountered in unilateral cases more than bilateral cases, and more than on the left than on the right side.

\section{References}

1) Adachi, B.: Das Arteriensystem der Japaner. Bd. 1, 85-96, Maruzen, Kyoto, 1928.

2) Fukuda, Y., K. Yoshida, H. Inoue, F. Suwa \& Y. Ohta: An experimental study on inserting an EMG electrode to the superior head of the human lateral pterygoid muscle. J. Jpn. Prosthodont. Soc., 34: 902-908, 1990 (in Japanese).

3) Fujita, T.: Über einen Fall von beiderseitig medial vom $N$ mandibularis verlaufender A. maxillaris interna, nebst einer Statistik der Verlaufsvariation der Arterie. J. Stomatol. Soc. Jpn., 4: 250-252, 1932 (in Japanese).

4) Ikakura, K.: On the origin, course and distribution of the maxillary artery in the Japanese. Arch. Dept. Anat. Tokyo Dent. Coll. (Kouku Kaibou Kenkyu), 18: 91-122, 1961 (in Japanese).

5) Iwamoto, S., M. Konishi, Y. Takahashi \& K. Kimura: Some variations in the course of the maxillary artery. J. Natl. Def. Coll., 6: 75-78, 1981 (in Japanese).

6) Kimura, K.: The inferior alveolar artery of the rabbit - from its origin to the mandibular foramen. Okajimas Folia Anat. Jpn., 59: 25-44, 1982.

7) Lasker, G., D. Opdyke \& H. Miller: The position of the internal maxillary artery and its questionable relation to the cephalic index. Anat. Rec., 109: 119-128, 1951.

8) Lauber, H.: Ueber einige Varietäten im Verlaufe der Arteria maxillaris interna. Anat. Anz., 19: 444-448, 1901.

9) Lippert, H. \& R. Pabst: Arterial Variations in Man. 86-87, Bergmann, München, 1985.

10) Long, J.J.: 1891, cited from reference 15).

11) Lurje, A.: On the topographical anatomy of the internal maxillary artery. Acta. Anat., 2: 219-231, 1947.

12) Saitoh, S.: On the posterior deep temporal artery of the cat. Jpn. J. Oral Biol., 30: 277-292, 1988 (in Japanese).

13) Suwa, F.: On the posterior deep temporal artery of the crabeating monkey. Okajimas Folia Anat. Jpn., 57: 347-368, 1981.

14) Suwa, F., S. Tominaga \& H. Kumagai: On the posterior deep temporal artery of the dog. Okajimas Folia Anat. Jpn., 55: 255-264, 1978.

15) Takarada, T.: The anatomical study of the maxillary artery in the Japanese. Shikagakuho, 58: 1-20, 1958 (in Japanese).

16) Takemura, A.: The rete mirabile of the maxillary artery in the 
cat. Okajimas Folia Anat. Jpn., 59: 103-136, 1982.

17) Takemura, A., F. Suwa, J. Nakajima, T. Otsuka \& S. Saitoh: Three cases of the maxillary artery in an abnormal course penetrating the mandibular nerve. Jpn. J. Oral Biol., 25:
1136-1139, 1983.

18) Thomson, A.: Report of the committee of collective investigation of the anatomical society of Great Britain and Ireland for the year 1889-1890. J. Anat. Phys., 25: 89-101, 1891.

\section{Key to Abbreviations in figures}

ec: External carotid artery

ia: Inferior alveolar artery

lb: Lingual branch

ma: Masseteric artery

$\mathrm{mm}$ : Middle meningeal artery

$\mathrm{mx}$ : Maxillary artery

pt: Posterior deep temporal artery

st: Superficial temporal artery $\mathrm{tt}$ : Common trunk between the inferior alveolar and the posterior deep temporal arteries

A: Inferior alveolar nerve

B: Buccal nerve

F1: Upper head

F2: Lower head

of the pterygoideus lateralis muscle

L: Lingual nerve

M: Pterygoideus medialis muscle 
Plate I
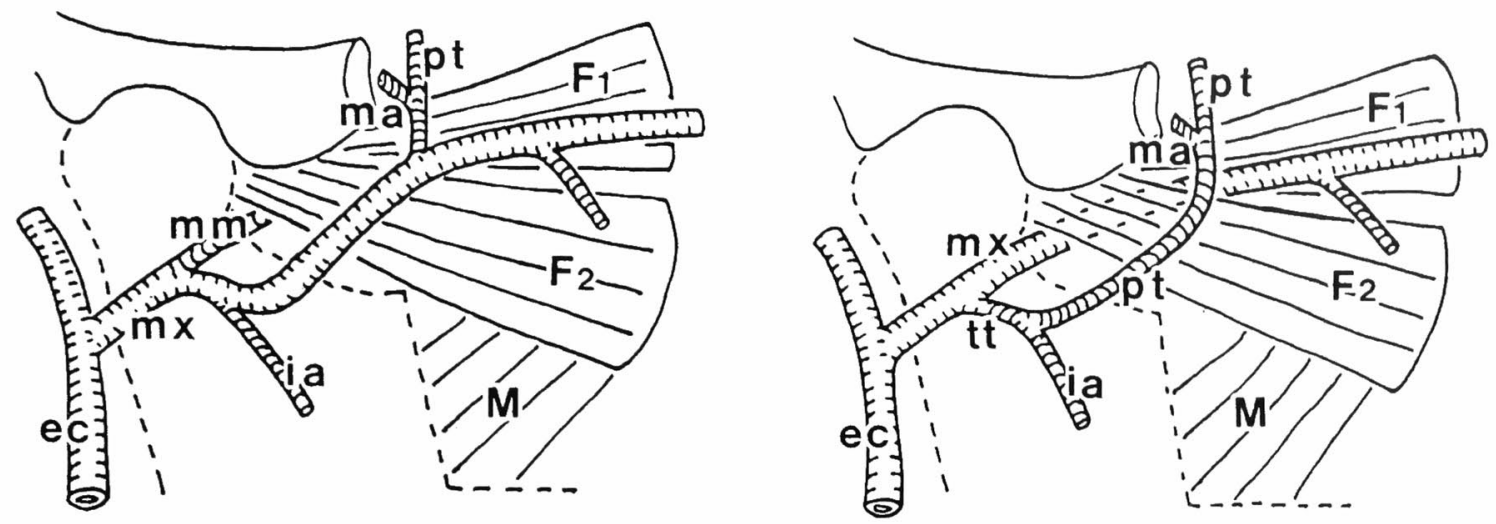

1 a

$1 b$

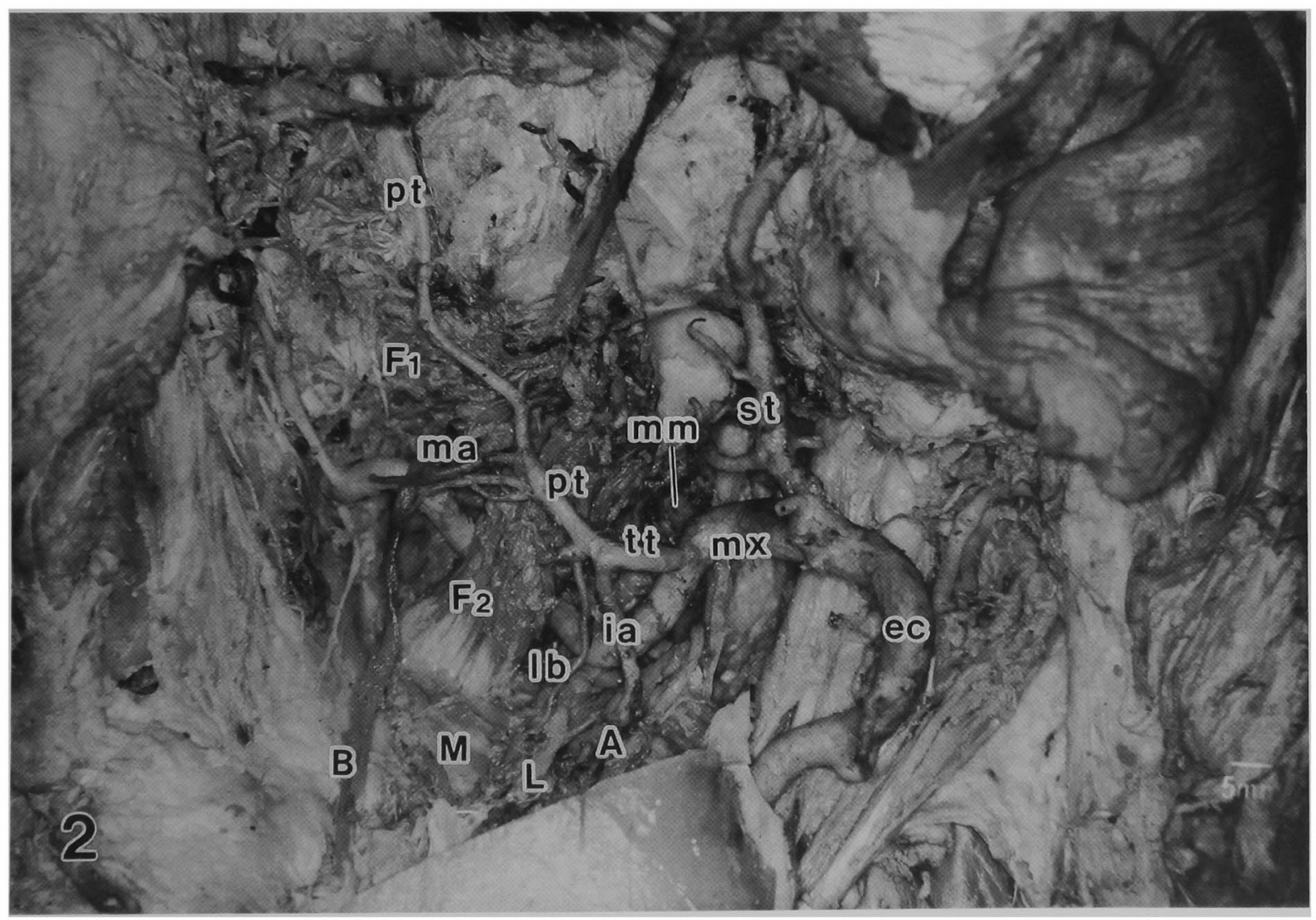

\section{Explanation of Figures}

Plate I

Fig. 1a and 1b. Schematic illustrations of the courses of the maxillary artery. Right side.

The maxillary artery in Fig. 1a passes lateral to the lower head of the pterygoideus lateralis muscle. The origin of the inferior alveolar is separated from that of the posterior deep temporal artery which gives rise to the masseteric artery.

The maxillary artery in Fig. 1b passes medial to the lower head of the muscle. The inferior alveolar and the posterior deep temporal arteries arise via a common trunk, and the masseteric arises from the latter.

Fig. 2. Lateral view of the maxillary artery and the pterygoideus lateralis muscle. Left side. $\times 12$.

The maxillary artery passes medial to the lower head of the pterygoideus lateralis muscle and penetrates it lateralwards. 